\title{
Sistem Pendukung Keputusan Pemilihan Atlit Lari Cepat Menggunakan Logika Fuzzy (Studi Kasus: Koni Sumatera Utara)
}

\section{Article Info \\ Article history:}

Received 26 February, 2021

Revised 27 March, 2021

Accepted 01 April, 2021

\section{Keywords:}

Decision Support System, Fuzzy Logic, Sprint Athlete Selection

\begin{abstract}
In every event such as the National Sports Week (PON), Regional Sports Week (PORDA), and other sports activities, the Indonesian National Sports Committee (KONI) of North Sumatra, always evaluates the results of the athlete's training, to determine which athletes are eligible. ready to take part in these activities or as a basis for recommendations for athlete participation. Furthermore, to determine the final result of the athlete's recommendation so far, it has also been done by counting manually through several stages and not everyone or the coach understands it, and sometimes there are errors in the process. Fuzzy logic is a set theory that can help in resolving the uncertainty of the boundary between one criterion and another that is generated by a cumulative human assessment of something. This theory can be used to help solve the problem of assessing the physical quality of athletes. One solution that can be done to overcome dependence on experts and the uncertainty of the boundary between one criterion and another is using fuzzy logic which is applied in the form of a visual program that can be used in determining the physical quality of athletes. To process physical test data into athlete recommendation data based on their physical quality, a decision support system is needed. namely using fuzzy logic which is applied in the form of a visual program that can be used in determining the physical quality of athletes.
\end{abstract}

This is an open access article under the CC BY-SA license.

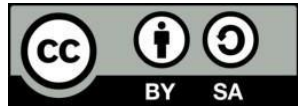

Corresponding Author:

Muhammad Iskandar Muda

Imelda University, Informatics Management, Medan, Indonesia

Email Address: kandar@gmail.com

(C) 2021 The Author: Published by. Cattleya Darmaya Fortuna

\section{Pendahuluan}

Di dalam organisasi atau bidang lari cepat, munculah atlit professional dalam dunia yang membutuhkan fasilitas pendukung khusus dalam melakukan aktivitasnya dengan baik [1]. Dalam memilih kandidat atlit tersebut dibutuhkan berbagai macam kriteria untuk menyeleksinya, yaitu kekuatan lari, stabilitas fisik, kelincahan gerakan, kecepatan, offense, defense, dan kesiapan. Semakin tinggi nilai hasil seleksi bertahap maka akan semakin tinggi pula prestasi [2] yang akan diraih. Para atlit yang lolos dalam seleksi nantinya akan dijadikan 


\section{Muhammad Iskandar Muda}

doi.org/10.54209/jatilima. V3i1.146

kandidat beserta para atlit di unit dalam sebuah tim untuk membela [3] negara. Sistem pendukung keputusan merupakan suatu sistem yang mampu memecahkan masalah secara efesian, efektif, yang bertujuan untuk membantu pengambilan keputusan dengan memilih berbagai alternatif keputusan [4]. Sistem pendukung keputusan memberikan suatu keputusan yang bersifat semiterstruktur, dimana tidak seorangpun tahu secara pasti bagaimana keputusan seharusnya dibuat [5]. SPK bertujuan untuk menyediakan informasi, membimbing, memberikan prediksi serta mengarahkan kepada pengguna informasi agar dapat melakukan pengambilan keputusan dengan lebih baik [6]. Logika merupakan studi penalaran [7]. Logika fuzzy merupakan bagian dari sistem kecerdasan buatan (Artificial Inteligent) yang mengemulasi kemampuan manusia dalam berfikir ke dalam bentuk algoritma yang kemudian dijalankan oleh mesin [8]. Logika fuzzy merupakan salah satu metode untuk melakukan analisa sistem yang mengandung ketidakpastian [9]. Karena ketidakpastian dari jumlah kebutuhan, maka dibutuhkan logika fuzzy untuk memecahkan masalah ini [10]. Logika fuzzy telah dikembangkan sejak lama dan digunakan di banyak bidang oleh para ahli dan insinyur [11]. Penggunaan logika fuzzy sangat berperan penting [12] dalam penyelesaian permasalahan ini. Dalam banyak hal logika fuzzy digunakan sebagai suatu cara untuk memecahkan permasalahan dari input menuju output yang diharapkan [13]. Penelitian ini bertujuan untuk mengimplementasikan metode Fuzzy ke sebuah sistem pengambil keputusan. Perancangan sistem pendukung keputusan dengan menggunakan [14] Metode Fuzzy yang merupakan logika bernilai banyak/multivalued logic yang mampu mendefinisikan nilai diantara keadaan yang konvensional seperti benar atau salah, ya atau tidak, putih atau hitam. Penalaran logika Fuzzy menyediakan cara untuk memahami kinerja sistem dengan cara menilai input dan output sistem dari hasil pengamatan. Variabel input yang digunakan untuk perhitungan Fuzzy pada sistem ini adalah Nilai Kecerdasan Logis Matematis, Nilai Kecerdasan Spasial Ruang, dan Tingkat Kecocokan, serta variabel output berupa Penentuan [15].

\section{Metode}

Analisis sistem dalam fuzzy berbeda dengan sistem lain pada umumnya. Mulai dari input data, pengolahan data, output data dan database. Model yang digunakan dalam penelitian ini adalah basis data fuzzy model Tahani untuk mempresentasikan sistem. Basis data fuzzy model Tahani masih tetap menggunakan relasi standar, hanya saja model ini menggunakan himpunan fuzzy untuk mendapatkan informasi dari query-nya. Himpunan fuzzy merupakan suatu grup yang mewakili suatu kondisi atau keadaan tertentu dalam suatu variabel fuzzy. Variabel-variabel yang di digunakan dalam sistem ini yaitu berupa butir tes yang berjumlah 7 buah komponen dan 18 sub komponen/buah butir tes, yaitu:

1. Komponen Kekuatan, dengan butir tes/teknik pengukuran: hand dynamometer, leg dynamometer, back dynamometer, hand grip.

2. Komponen Kecepatan, dengan butir tes/teknik pengukuran: lari 400 meter.

3. Komponen Power, dengan butir tes/teknik pengukuran: medicine ball put, vertical jumps.

4. Komponen Kelentukan/Flexibilitas, dengan butir tes/teknik pengukuran: flexometer, flexed arm hang, flexion of thrunk.

5. Kelincahan/Agilitas, dengan butir tes/teknik pengukuran: shuttle run.

6. Daya Tahan Otot, dengan butir tes/teknik pengukuran: pull ups, push ups, sit ups, squat jumps, back lifts.

7. Daya Tahan Umum, dengan butir tes/teknik pengukuran: lari 15 menit (VO2max), bleep 


\section{Muhammad Iskandar Muda}

doi.org/10.54209/jatilima. V3i1.146

test.

Program ini direkomendasikan untuk dijalankan dengan menggunakan perangkat keras (hardware) dan perangkat lunak (software) dengan spesifikasi berikut:

1. Minimal menggunakan Prosesor Core Duo 1,6 Ghz

2. Dengan Memory $1 \mathrm{~GB}$.

3. Harddisk $10 \mathrm{~GB}$.

4. VGA card1 GB.

5. Monitor dengan resolusi $800 \times 600$ pixel.

6. Keyboard dan Mouse.

7. Sistem Operasi Windows 7

\section{Hasil dan Pembahasan}

Algoritma adalah urutan langkah-langkah logika yang diperlukan untuk penyelesaian masalah dan penyusunan program. Algoritma digunakan untuk menganalisa serta menjelaskan urutan dan hubungan antara kegiatan yang akan ditempuh. Penyusunan algoritma ini sangat penting dalam perancangan suatu program. Selain itu algoritma juga berfungsi untuk menyelesaikan suatu permasalah hingga tercapai suatu tujuan. Adapun algoritma Logika Fuzzy adalah sebagai berikut :

\section{Input}

a. Kekuatan

b. Kecepatan

c. Jump

d. Kelentukan

e. Kelincahan

f. Daya Tahan

\section{Output}

Simpan Nilai

$=\mathrm{a}, \mathrm{b}, \mathrm{c}, \mathrm{d}, \mathrm{e}, \mathrm{f}$

\section{Proses}

For $\mathrm{a}=1$ to $\mathrm{n}$ do

Seek a

If found()

Loop

Pesan "Data Sudah Di Input"

Else

\section{End}

\section{Implementasi}

Dalam hal ini penulis akan menjabarkan tentang langkah-langkah pembuatan program hingga implementasi yang akan dilakukan dalam menyelesaikan rancangan SPK pada Seleksi Calon 


\section{Muhammad Iskandar Muda}

doi.org/10.54209/jatilima. V3i1.146

atlet Lari Cepat Jarak Tempuh 400 Meter Dengan logika fuzzy adalah:

1. Menyelesaikan Desain Sistem

2. Menyediakan Perangkat Keras (hardware) dan Perangkat Lunak (Software)

3. Menuliskan Listing Progaram Kekomputer

4. Menguji Sistem

5. Melakukan Bimbingan Terhadap Langkah-Langkah Pengoperasian Sistem

6. Perawatan Sistem

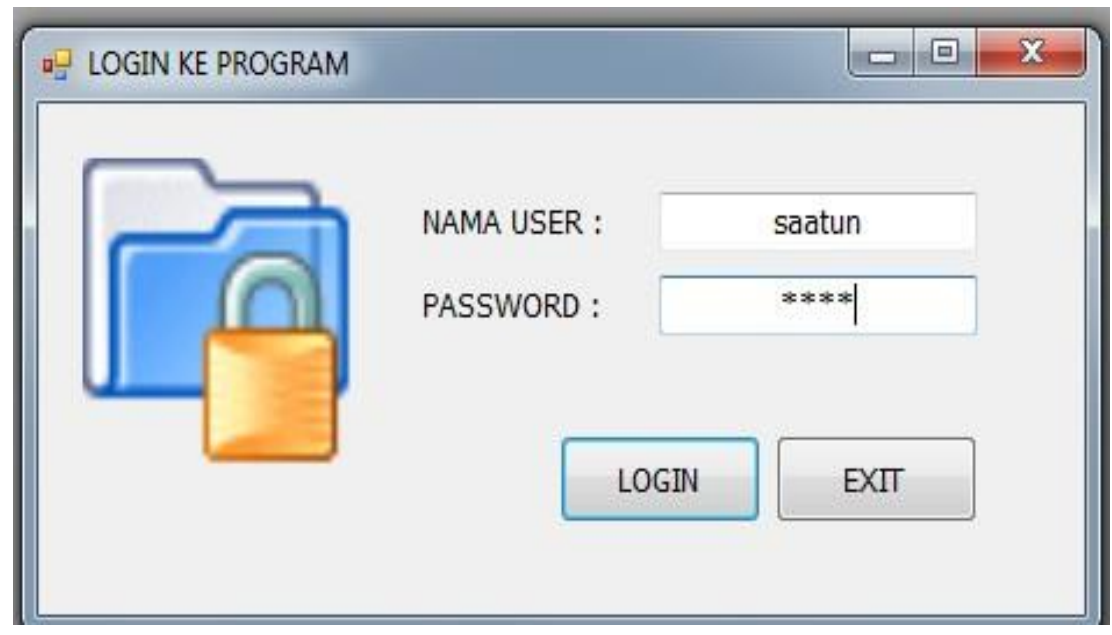

Gambar 1. Form Login

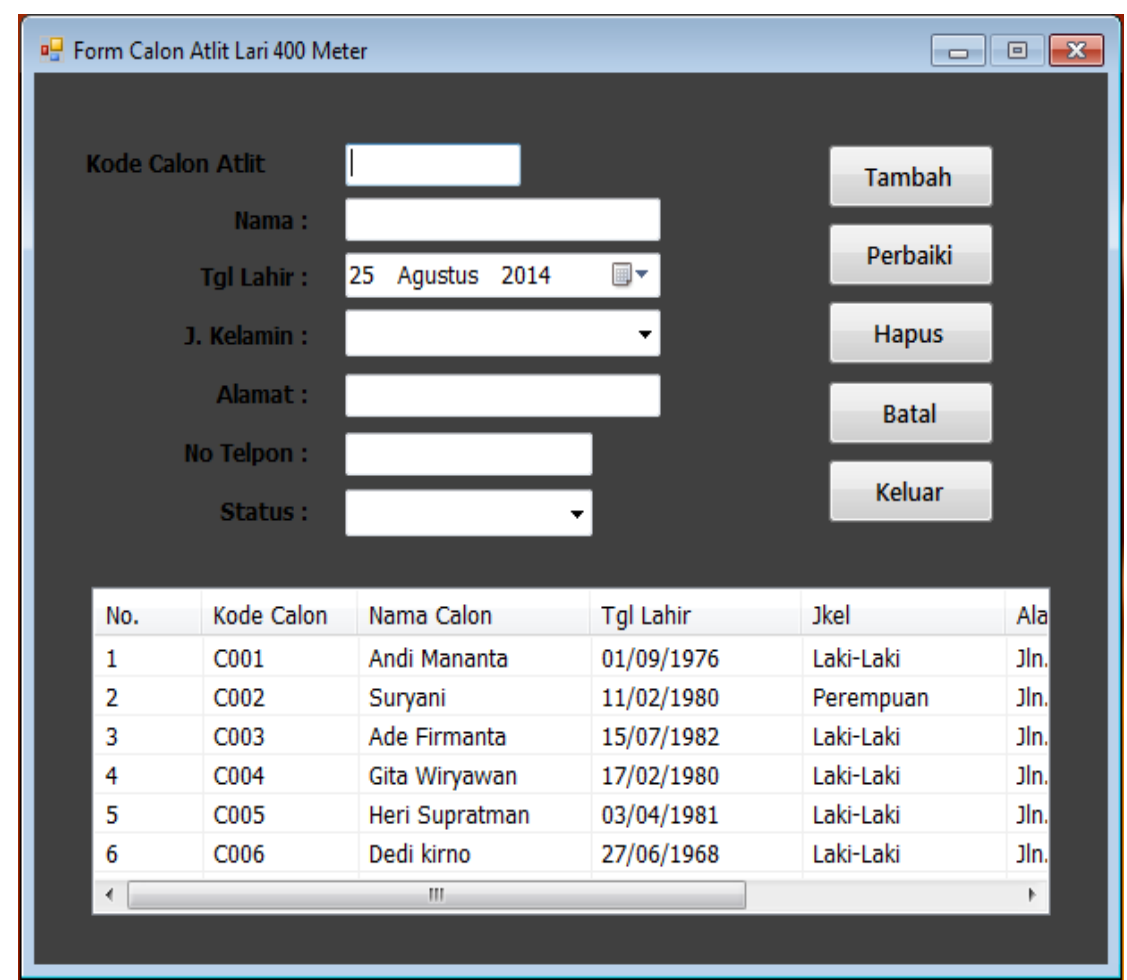

Gambar 2. Tampilan Menu Calon Atlit Lari 400 M

Form Data Calon Kepala Sekolah Form Data Seleksi Calon atlet Lari Jarak Tempuh 400 Meter adalah tampilan untuk menginputkan data-data Calon atlet Lari yang akan diseleksi 


\section{Muhammad Iskandar Muda}

doi.org/10.54209/jatilima. V3i1.146

kedalam database.

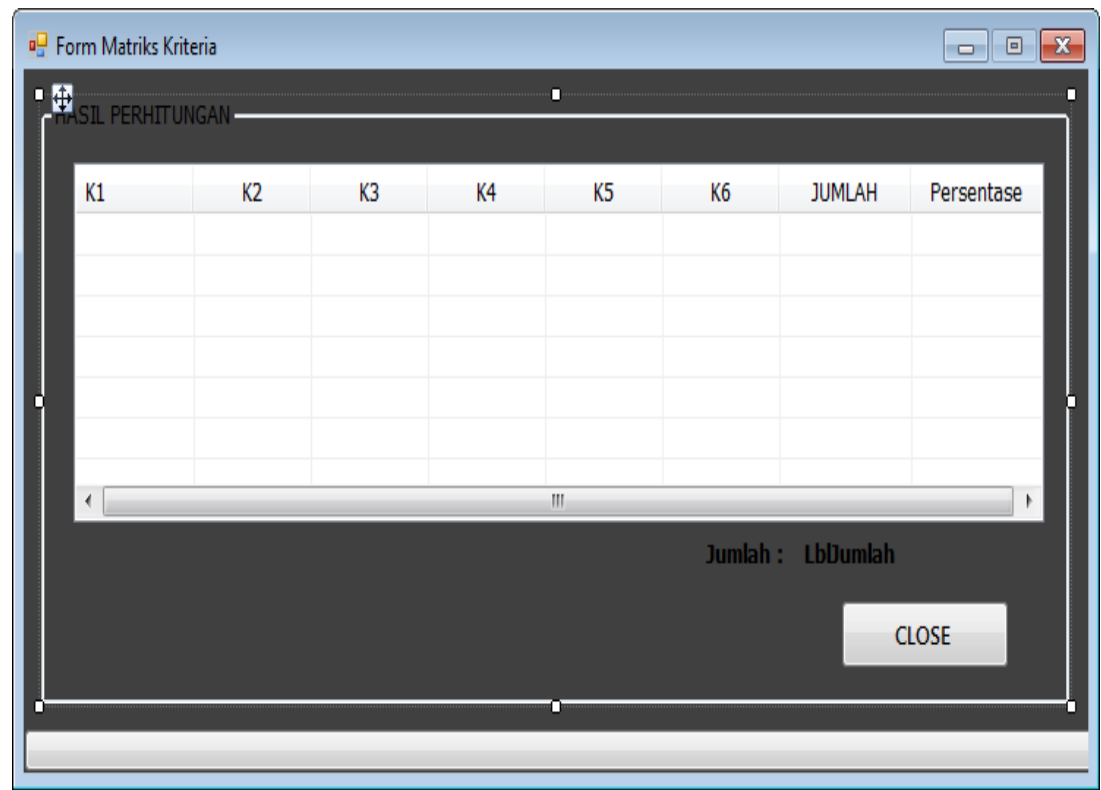

Gambar 3. Form Menu Matrik Kriteria

Pada form matriks Kriteria Calon Atlit Lari $400 \mathrm{M}$ adalah form untuk menginputkan data penilaian Calon Atlit Lari $400 \mathrm{M}$ berdasarkan kriteria yang ditentukan oleh Koni.

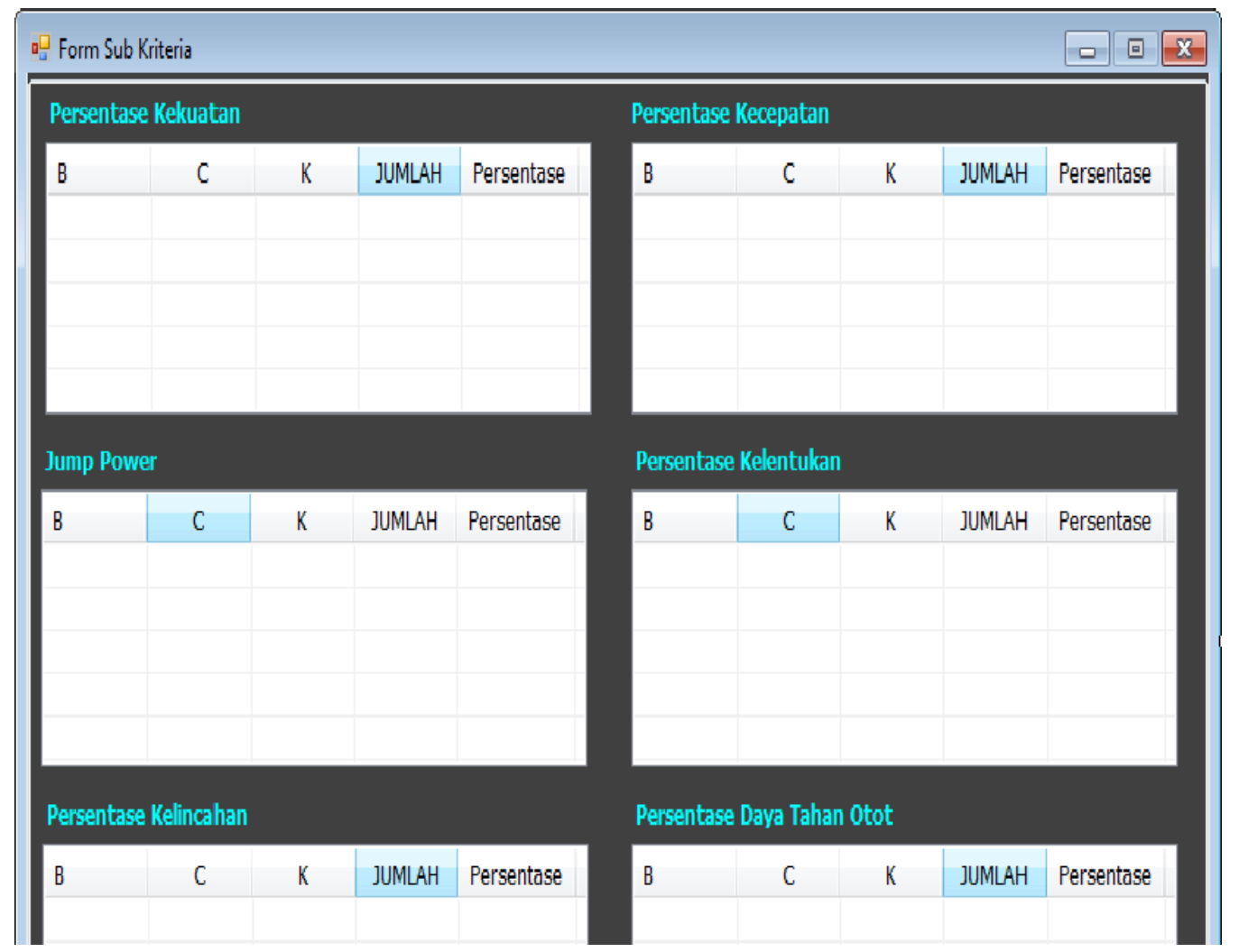

Gambar 4. Form Menu Sub Kriteria 


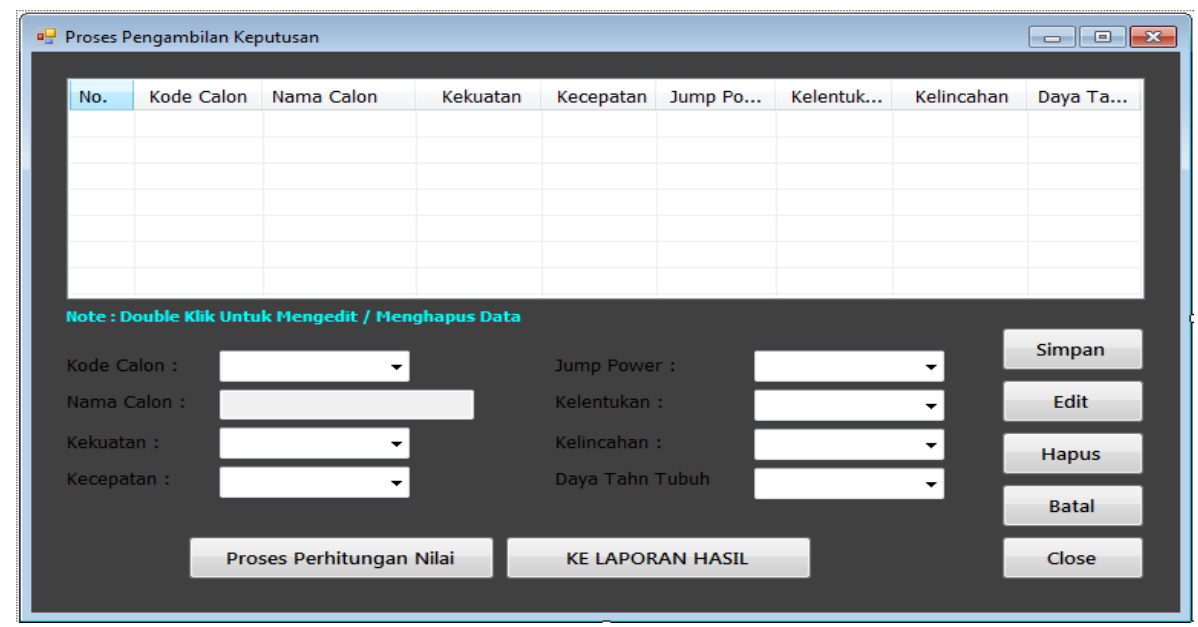

Gambar 5. Form Menu Proses Pengambilan Keputusan

\section{Kesimpulan}

Perancangan aplikasi Sistem Pendukung Keputusan Seleksi Calon atlet Lari Cepat Jarak Tempuh 400 Meter Dengan Logika Fuzzy yang telah diselesaikan ini dapatlah diambil beberapa kesimpulan diantaaranya adalah: Sistem Pendukung Keputusan ini merupakan sistem yang dirancang untuk membantu Koni dalam mengambil keputusan Seleksi Calon atlet Lari Cepat Jarak Tempuh 400 Meter. Hasil perhitungan Logika Fuzzy yang diterapkan ini akan menghasilkan keluaran nilai kriteria-kriteria Seleksi Calon atlet Lari yang tertinggi dan profesional sehingga siapa yang layak memenuhi kriteria tersebut yang bisa menjadi Atlit Lari. Dengan aplikasi yang dirancang pada aplikasi Sistem Pendukung Keputusan Seleksi Calon atlet Lari Cepat Jarak Tempuh 400 Meter dengan metode Logika Fuzzy dapat mempermudah Koni untuk mengetahui mengetahui siapa yang pantas dan tidak untuk menjadi Atlit Lari yang professional dan menghasilkan hasil penilaian yang akurat.

\section{Reference}

[1] F. R. Santoso, G. Mulyono, and F. Tanaya, "Perancangan Set Produk Interior Ergonomis Untuk Profesional Gamer," J. Intra, vol. 6, no. 2, 2018.

[2] D. Mulyadi, "Komparasi Metode Logika Fuzzy Mamdani dan Metode Logika Fuzzy Sugeno Sebagai Pendukung Keputusan Seleksi Bertahap," Teknois J. Ilm. Teknol. Inf. dan Sains, vol. 6, no. 1, 2019.

[3] R. P. Nugraha, R. Regasari, M. Putri, and L. Muflikhah, "Pemilihan Tim Bulutangkis Menggunakan Metode Fuzzy Tsukamoto dan AHP-SAW," J. Pengemb. Teknol. Inf. dan Ilmu Komput., vol. 2, no. 6, 2018.

[4] Sriani and R. A. Putri, "Analisa Sistem Pendukung Keputusan Menggunakan Metode Topsis Untuk Sistem Penerimaan Pegawai Pada Sma Al Washliyah Tanjung Morawa," J. Ilmu Komput. dan Inform., vol. 02, no. April, 2018.

[5] F. I.-R. P. Computer, "Sistem Pendukung Keputusan Penerimaan Jurnalis Menerapkan MultiObjective Optimization On The Basis Of Ratio Analysis (MOORA)," JURIKOM (Jurnal Ris. Komputer), vol. 5, no. 1, 2018. 


\section{Muhammad Iskandar Muda}

doi.org/10.54209/jatilima. V3i1.146

[6] S. W. Sari and B. Purba, "Sistem Pendukung Keputusan Pemilihan Ketua Danru Terbaik Menggunakan Metode ARAS," Semin. Nas. Teknol. Komput. Sains SAINTEKS 2019, 2019.

[7] A. Setiawan, B. Yanto, and K. Yasdomi, Logika Fuzzy Dengan Matlab (Contoh Kasus Penelitian Penyakit Bayi dengan Fuzzy Tsukamoto). 2018.

[8] S. Amalia, R. Andari, and R. Syukriansyah, "STUDI PEMODELAN SISTEM PENGONTROLAN SUHU RUANGAN BERBASIS LOGIKA FUZZY SUGENO,” J. Sains dan Teknol. J. Keilmuan dan Apl. Teknol. Ind., vol. 20, no. 2, 2020.

[9] D. E. Myori and Hastuti, "Kombinasi Logika Fuzzy dan Algoritma Genetika Untuk Masalah Penjadwalan Perkuliahan," Semin. Nas. Tek. Elektro UIN Sunan Gunung Djati Bandung (SENTER 2018), 2019.

[10] S. Nurhayati and I. Immanudin, "Penerapan Logika Fuzzy Mamdani Untuk Prediksi Pengadaan Peralatan Rumah Tangga Rumah Sakit," Komputika J. Sist. Komput., vol. 8, no. 2, 2019.

[11] B. Setia, "Penerapan Logika Fuzzy pada Sistem Cerdas," J. Sist. Cerdas, vol. 2, no. 1, 2019.

[12] D. Kurnia and J. Hendrawan, "Perancangan Dan Penerapan Sistem Pengering Ikan Otomatis Menggunakan Logika Fuzzy Pada Mikrokontroller," J. Ilm. Core It, vol. 6, no. II, 2018.

[13] D. L. Rahakbauw, V. Y. I. Ilwaru, and M. H. Hahury, "IMPLEMENTASI FUZZY CMEANS CLUSTERING DALAM PENENTUAN BEASISWA," BAREKENG J. Ilmu Mat. dan Terap., vol. 11, no. 1, 2017.

[14] G. P. Dana, "Pengembangan Sistem Pendukung Keputusan untuk Penentuan Jumlah Produksi Kain dengan Metode Inferensi Fuzzy Mamdani,” 2012.

[15] "Sistem Pendukung Keputusan Penentuan Kelolosan Beasiswa Sekolah Menengah Kejuruan (SMK) menggunakan Metode Fuzzy,” J. Tek. Elektro, vol. 9, no. 1, 2017. 